Revista Destaques Acadêmicos, Lajeado, v. 9, n. 4, 2017. ISSN 2176-3070 DOI: http://dx.doi.org/10.22410/issn.2176-3070.v9i4a2017.1671 www.univates.br/revistas

\title{
AVALIAÇÃO DO POTENCIAL DE UTILIZAÇÃO DE PRÉ- TRATAMENTO OSMÓTICO NA PRODUÇÃO DE MANGA DESIDRATADA
}

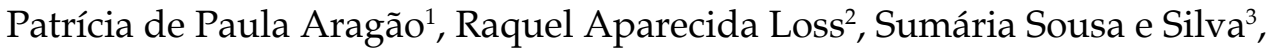 \\ Sumaya Ferreira Guedes ${ }^{4}$
}

Resumo: A manga é uma fruta muito perecível que gera resíduos por não ser devidamente explorada industrialmente, apesar do seu alto teor de nutrientes. Diante disso, este trabalho teve como objetivo analisar as variáveis que influenciam no processo de desidratação osmótica da manga, tipo espada. Inicialmente foram empregados diferentes planejamentos experimentais, a fim de obter a melhor condição para a remoção de água da fruta através do processo de osmose. As variáveis analisadas foram: concentração de sacarose, tamanho do fruto, proporção fruto:xarope e tempo de imersão, sendo os mesmos avaliados em termos de umidade (\%). A melhor condição experimental foi submetida a secagem $\left(40{ }^{\circ} \mathrm{C}\right.$ e $\left.60{ }^{\circ} \mathrm{C}\right)$ com circulação de ar com velocidade constante de $3,2 \mathrm{~m} / \mathrm{s}$. A maior perda de umidade foi obtida após 14 horas de imersão, teor de sacarose $70 \%$ e tamanho de $0,5 \mathrm{~cm}$ e proporção fruto:xarope de 1:2 (g:mL). Os resultados das análises físico-químicas mostraram uma acentuada perda de acidez das amostras desidratadas e aumento do teor de cinzas, indicando que esse

1 Graduada em Engenharia de Alimentos (Universidade do Estado de Mato Grosso- UNEMAT). Mestre em Tecnologia e Segurança Alimentar e Doutoranda pela Universidade Nova de Lisboa (UNL), Portugal.

2 Graduada em Engenharia de Alimentos (Universidade de Passo Fundo- UPF). Mestre em Engenharia de Alimentos (Universidade Federal de Santa Catarina, UFSC). Doutora em Engenharia de Alimentos (Universidade Federal de Santa Catarina, UFSC). Professora da Universidade do Estado de Mato Grosso (UNEMAT), Campus de Barra do Bugres- MT.

3 Graduada em Licenciatura Plena em Química (Universidade Estadual do Piauí-UESPI). Mestre em Ciências (Universidade de São Paulo-USP). Doutora em Ciências (Universidade de São Paulo-USP). Professora da Universidade do Estado de Mato Grosso (UNEMAT), Campus de Barra do Bugres- MT.

4 Graduada em Licenciatura Plena em Química (Universidade Federal de Mato Grosso- UFMT). Mestre em Tecnologia e Segurança Alimentar (Universidade Nova de Lisboa, UNL, Portugal). Doutora em Química (Universidade Estadual de Campinas- UNICAMP). Professora da Universidade do Estado de Mato Grosso (UNEMAT), Campus de Barra do Bugres- MT. 
processo influencia no teor de nutrientes presentes na manga. Durante a secagem da amostra com tratamento osmótico houve uma maior perda de água do que a in natura, em ambas as temperaturas avaliadas. Dessa forma, o processo de desidratação osmótica pode ser considerado como uma alternativa para a conservação da manga espada, uma vez que é simples e capaz de reduzir a umidade inicial da manga.

Palavras-chave: Mangifera indica L. Desidratação osmótica. Secagem convectiva.

\section{INTRODUÇÃO}

As frutas são geralmente consumidas frescas, devido à alta perecibilidade, falta de manipuladores treinados e infra-estrutura para seu processamento e preservação, o que têm gerado uma perda em torno de $30 \%$ da produção, em alguns casos, um excesso de 50 \%. A manga, apesar de apresentar alto teor de nutrientes é um dos frutos que tem gerado grande acúmulo de resíduos por ainda não ser devidamente explorada industrialmente (DAMIANI et al., 2008; BEZERRA et al., 2009; SANTOS et al., 2011).

Devido as mudanças nos hábitos alimentares nos grandes centros urbanos, a industrialização das frutas é de extrema importância para o país. Como forma de reduzir as perdas e aumentar sua vida útil, a indústria de alimentos realiza técnicas de conservação tais como congelamento, irradiação, enlatamento e desidratação (SILVA et al., 2011). As técnicas empregadas viabilizam a conservação das propriedades nutricionais e sensoriais dos alimentos, favorecendo a oferta em épocas de entressafra, surgindo como alternativa para solucionar os problemas advindos do desperdício e distribuição, além agregar valor ao produto (BEZERRA et al., 2009).

A desidratação osmótica, como ferramenta tecnológica para o desenvolvimento de novos produtos vem sendo estudada para derivados de frutas, sendo geralmente utilizada como um pré-tratamento, preservando as características nutricionais e funcionais (SOUSA NETO et al., 2005).

Diante disso, propõe-se avaliar a influência das variáveis no processo de desidratação osmótica da manga espada combinados com o processo de secagem.

\section{MATERIAIS E MÉTODOS}

\subsection{Obtenção, seleção e preparo da matéria-prima}

A manga espada (Mangifera indica L.) foi obtida diretamente das mangueiras localizadas em residências do município de Barra do Bugres - MT. Este município localiza-se na mesorregião do sudoeste do Estado de Mato Grosso, e situa-se a $150 \mathrm{~km}$ da capital do Estado de Mato Grosso, Cuiabá (IBGE, 2010), sendo selecionadas manualmente por meio de escolha das frutas isentas de doenças, integras, com aroma característicos e textura firme em estágio de maturação para consumo, considerada madura (casca amarela). Inicialmente, 
os frutos foram higienizados, lavados com detergente, em água corrente, submersos em água clorada por 15 minutos (cloro ativo a $50 \mathrm{mg} \mathrm{L}^{-1}$ ) e secos, seguindo a mesma metodologia adotada por Sousa Neto et al., (2005).

Com o auxílio de uma faca, as frutas foram descascadas, cortadas e divididas em partes de acordo com os planejamentos experimentais $(0,5$, $1,0,1,5,3,0$ e 5,0 cm), sendo então utilizadas para análises físico-químicas e desidratação osmótica, seguida de secagem convectiva.

\subsection{Preparo da solução osmótica}

As soluções osmóticas foram elaboradas em diferentes concentrações de sacarose, 40, 50, 60 e $70 \%(\mathrm{~m} / \mathrm{v})$. As soluções foram preparadas com água destilada, com agitação manual, e um breve aquecimento, até completa solubilização. Posteriormente, as soluções foram acondicionadas à temperatura ambiente, em recipientes de vidro âmbar, sendo preparadas no dia anterior ao seu uso. O agente osmótico utilizado foi sacarose comercial, adquirida no mercado local de Barra do Bugres- MT.

\subsection{Avaliação das variáveis que interferem na desidratação osmótica}

Para avaliar as variáveis que interferem na desidratação osmótica da manga inicialmente optou-se por um planejamento fatorial fracionado $2^{4}$ 1 , onde as variáveis estudadas foram a concentração da solução de sacarose, proporção fruta:xarope, tamanho das peças de manga e tempo de desidratação (TABELA 1).

Tabela 1: Variáveis e níveis estudados no planejamento fatorial fracionado $2^{4-1}$ no pré-tratamento osmótico

\begin{tabular}{c|c|c|c|c}
\hline Variáveis/Níveis & $\begin{array}{c}\text { Sacarose } \\
\mathbf{( \% )}\end{array}$ & $\begin{array}{c}\text { Fruto:xarope } \\
\mathbf{( g / m L )}\end{array}$ & $\begin{array}{c}\text { Tamanho } \\
\text { (cm) }\end{array}$ & $\begin{array}{c}\text { Tempo } \\
\text { (h) }\end{array}$ \\
\hline-1 & 40 & $1: 2$ & 1 & 40 \\
\hline 0 & 50 & $1: 4$ & 5,5 & 70 \\
\hline 1 & 60 & $1: 6$ & 10 & 100 \\
\hline
\end{tabular}

Fonte: Próprio autor, 2017.

Os resultados obtidos neste planejamento foram avaliados em termos de umidade (\%) e submetidos à análise estatística no software Statistica 7,0. A partir destes resultados foi realizado um planejamento fatorial completo $2^{3}$, estudando as variáveis: concentração de sacarose, tamanho das peças e tempo de desidratação, conforme Tabela 2 . Todos os ensaios foram realizados na razão fruta:xarope de 1:2. 
Tabela 2: Variáveis e níveis estudados no planejamento fatorial $2^{3}$ no prétratamento osmótico

\begin{tabular}{c|c|c|c}
\hline Variáveis/Níveis & $\begin{array}{c}\text { Sacarose } \\
\mathbf{( \% )}\end{array}$ & $\begin{array}{c}\text { Tamanho } \\
\text { (cm) }\end{array}$ & $\begin{array}{c}\text { Tempo } \\
\text { (h) }\end{array}$ \\
\hline-1 & 50 & 0,50 & 6 \\
\hline 0 & 60 & 1 & 10 \\
\hline 1 & 70 & 1,5 & 14 \\
\hline
\end{tabular}

Fonte: Próprio autor, 2017.

Os resultados obtidos neste planejamento também foram avaliados e em termos de umidade (\%) e submetidos à análise estatística.

Em cada planejamento, a solução contendo a manga foi agitada manualmente por 10 minutos a cada hora de imersão para facilitar o processo de osmose com a recirculação do xarope conforme a metodologia descrita por Sousa Neto et al., (2005).

No final dos tempos de imersão determinados, as soluções foram drenadas com o auxílio de uma peneira por aproximadamente cinco minutos, os frutos foram colocados sob papel absorvente para retirada o excesso de solução, e as frutas foram então maceradas e acondicionadas em recipientes de plástico sob armazenamento a $-20^{\circ} \mathrm{C}$, para análises físico-química.

$\mathrm{O}$ ensaio que apresentou a menor umidade foi realizado novamente em triplicata e a amostra submetida à secagem convectiva em estufa com circulação de ar.

\subsection{Cinética de secagem}

Os frutos desidratados osmoticamente foram inseridos em bandejas de plástico e secos em estufa com circulação de ar QUIMIS (Brasil), com velocidade do ar de secagem constante de $3,2 \mathrm{~m} / \mathrm{s}$, nas temperaturas de 40 e $60^{\circ} \mathrm{C}$. Os pesos das bandejas foram monitorados nos tempos 15, 30, 60, 120 e 180 minutos para retirada da umidade até a obtenção do peso constante. As curvas de secagem foram realizadas em triplicata.

\subsection{Análise físico-química}

As análises físico-químicas de umidade, cinzas, $\mathrm{pH}$ e acidez titulável seguiu os procedimentos descritos pelo Instituto Adolfo Lutz (2008). Todas as análises foram realizadas em triplicata com intuito de minimizar erros experimentais. 


\subsection{Análise estatística}

Os dados obtidos foram submetidos à análise de variância (ANOVA) e teste de comparação entre médias, teste de Tukey, numa significância de 5\%, através do software Statistica 7.0.

\section{RESULTADOS E DISCUSSÃO}

\subsection{Avaliação das variáveis que interferem na desidratação osmótica}

Inicialmente, a umidade da fruta in natura era de 85,48 \%. Após desidratação osmótica foi possível reduzir esta umidade para 57,21 \% (TABELA 3). Na análise das variáveis é possível observar que experimentos 2, 4 e 8 apresentam as melhores condições para o processo de desidratação osmótica (menor umidade).

Tabela 3: Matriz do planejamento fatorial fracionado $2^{4-1} \mathrm{com}$ as variáveis reais e codificadas para a desidratação osmótica, com as respostas expressas em termos de umidade

\begin{tabular}{|c|c|c|c|c|c|}
\hline Experimentos & $\begin{array}{c}\text { Sacarose } \\
(\%)\end{array}$ & $\begin{array}{c}\text { Fruta:Xarope } \\
\text { (g:mL) }\end{array}$ & $\begin{array}{l}\text { Tamanho } \\
\text { (cm) }\end{array}$ & $\begin{array}{c}\text { Tempo } \\
\text { (h) }\end{array}$ & $\begin{array}{l}\text { Umidade } \\
(\%)\end{array}$ \\
\hline in natura & & & & & $85,48 \pm 0,25$ \\
\hline 1 & $-1(40)$ & $-1(1: 2)$ & $-1(1)$ & $-1(2)$ & $67,99 \pm 0,37$ \\
\hline 2 & $1(60)$ & $-1(1: 2)$ & $-1(1)$ & $1(6)$ & $57,86 \pm 0,43$ \\
\hline 3 & $-1(40)$ & $1(1: 6)$ & $-1(1)$ & $1(6)$ & $64,46 \pm 0,63$ \\
\hline 4 & $1(60)$ & $1(1: 6)$ & $-1(1)$ & $-1(2)$ & $60,75 \pm 0,26$ \\
\hline 5 & $-1(40)$ & $-1(1: 2)$ & $1(5)$ & $1(6)$ & $69,98 \pm 0,78$ \\
\hline 6 & $1(60)$ & $-1(1: 2)$ & $1(5)$ & $-1(2)$ & $69,02 \pm 0,21$ \\
\hline 7 & $-1(40)$ & $1(1: 6)$ & $1(5)$ & $-1(2)$ & $71,61 \pm 0,17$ \\
\hline 8 & $1(60)$ & $1(1: 6)$ & $1(5)$ & $1(6)$ & $60,46 \pm 0,52$ \\
\hline 9 & $0(50)$ & $0(1: 4)$ & $0(3)$ & $0(4)$ & $65,95 \pm 0,14$ \\
\hline 10 & $0(50)$ & $0(1: 4)$ & $0(3)$ & $0(4)$ & $64,90 \pm 0,09$ \\
\hline 11 & $0(50)$ & $0(1: 4)$ & $0(3)$ & $0(4)$ & $64,04 \pm 0,99$ \\
\hline
\end{tabular}

Fonte: Próprio autor, 2017.

Os resultados de umidade obtidos foram submetidos a análise estatística considerando a influência dos parâmetros avaliados em relação a perda de umidade do fruto, conforme mostra a Figura 1. 
Figura 1: Diagrama de Pareto dos efeitos das variáveis sobre a perda de água na desidratação osmótica de manga.

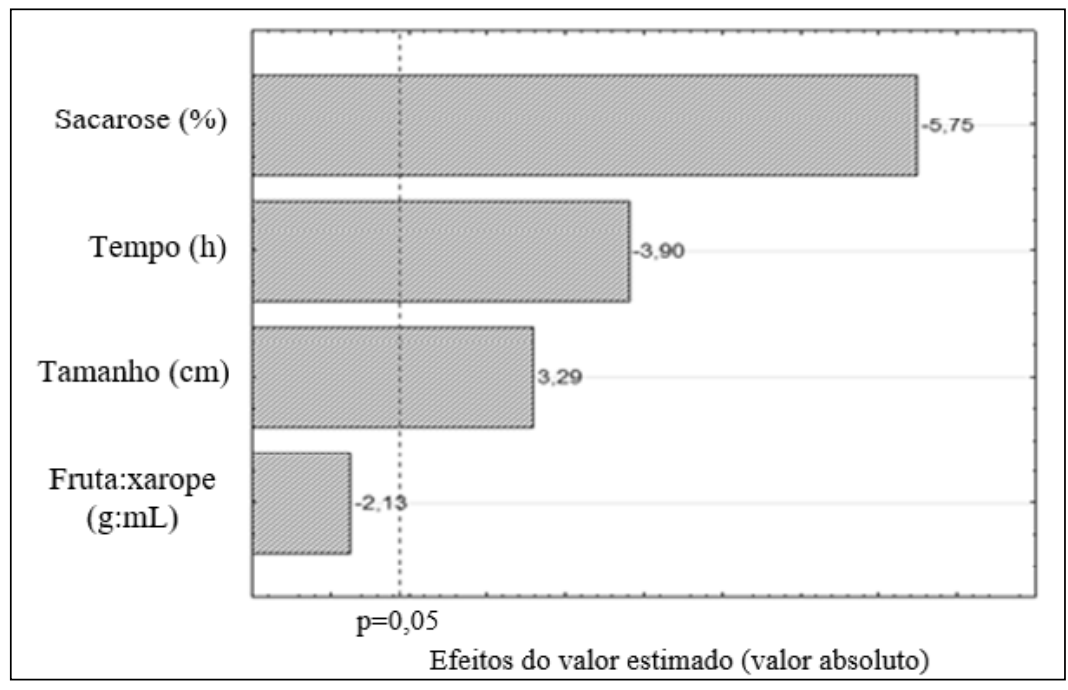

Fonte: Próprio autor, 2017.

Pela Figura 1 verifica-se que a variável concentração da solução de sacarose foi a que exerceu maior influência sobre a perda de umidade, apresentando uma influência significativa, ou seja, a mudança dessa variável de um nível menor para um nível maior ocasionou um incremento nos valores de perda de água. O tempo de imersão e tamanho das peças de manga também exerceram influência significativa, sendo que tempo maiores e tamanhos menores podem conduzir a uma maior perda de água da manga submetida a desidratação osmótica. Já a relação fruto:xarope não foi significativa sobre a resposta perda de umidade. Em estudos realizados por Araújo et al., (2010), em cenouras desidratadas osmoticamente os parâmetros tempo e concentração de sacarose foram as variáveis que influenciaram os valores de perda de água, o que também foi observado neste trabalho.

A partir destes resultados desenvolveu-se um novo planejamento modificando os valores das variáveis, resultando em maior concentração de sacarose na solução e maior período de permanência das amostras com objetivo de obter menores teores de água. $\mathrm{O}$ tamanho das peças foram reduzidos e a proporção fruto:xarope foi fixado em 1:2, uma vez que esta variável não é significativa e contribuiu para umas das maiores remoções de umidade $(39,97$ $\%)$. As umidades obtidas neste segundo planejamento encontram-se descritos na Tabela 4. 
Tabela 4: Matriz do planejamento fatorial completo $2^{3} \mathrm{com}$ as variáveis reais e codificadas para a desidratação osmótica, com as respostas expressas em termos de umidade

\begin{tabular}{c|c|c|c|c}
\hline Experimentos & $\begin{array}{c}\text { Sacarose } \\
(\mathbf{\%})\end{array}$ & $\begin{array}{c}\text { Tempo } \\
(\mathbf{h})\end{array}$ & $\begin{array}{c}\text { Tamanho } \\
(\mathbf{c m})\end{array}$ & $\begin{array}{c}\text { Umidade } \\
\mathbf{( \% )}\end{array}$ \\
\hline 1 & $-1(50)$ & $-1(6)$ & $-1(0,5)$ & $56,85 \pm 027$ \\
\hline 2 & $+1(70)$ & $-1(6)$ & $-1(0,5)$ & $48,52 \pm 0,57$ \\
\hline 3 & $-1(50)$ & $+1(14)$ & $-1(0,5)$ & $52,24 \pm 0,22$ \\
\hline 4 & $+1(70)$ & $+1(14)$ & $-1(0,5)$ & $39,97 \pm 1,26$ \\
\hline 5 & $-1(50)$ & $-1(6)$ & $+1(1,5)$ & $63,02 \pm 0,92$ \\
\hline 6 & $+1(70)$ & $-1(6)$ & $+1(1,5)$ & $52,83 \pm 2,87$ \\
\hline 7 & $-1(50)$ & $+1(14)$ & $+1(1,5)$ & $59,75 \pm 1,74$ \\
\hline 8 & $+1(70)$ & $+1(14)$ & $+1(1,5)$ & $47,07 \pm 0,68$ \\
\hline 9 & $0(60)$ & $0(10)$ & $0(1,0)$ & $51,89 \pm 1,24$ \\
\hline 10 & $0(60$ & $0(10)$ & $0(1,0)$ & $50,77 \pm 0,95$ \\
\hline 11 & $0(60)$ & $0(10)$ & $0(1,0)$ & $50,22 \pm 0,82$ \\
\hline
\end{tabular}

Fonte: Próprio autor, 2017.

A análise estatística (FIGURA 2) mostrou que todas as variáveis apresentaram efeitos significativos. Quanto mais concentrada a solução osmótica, maior o tempo de incubação e menor o tamanho dos pedaços de manga. Porém, frutos com tamanhos menores que $0,5 \mathrm{~cm}$, tempos de imersão superiores a 14 horas tornam o método ineficiente industrialmente, além de não ser possível obter soluções de sacarose com concentrações acima de $70 \%$ devido ao processo de recristalização. 
Figura 2: Diagrama de Pareto dos efeitos das variáveis sobre a perda de água na desidratação osmótica de manga

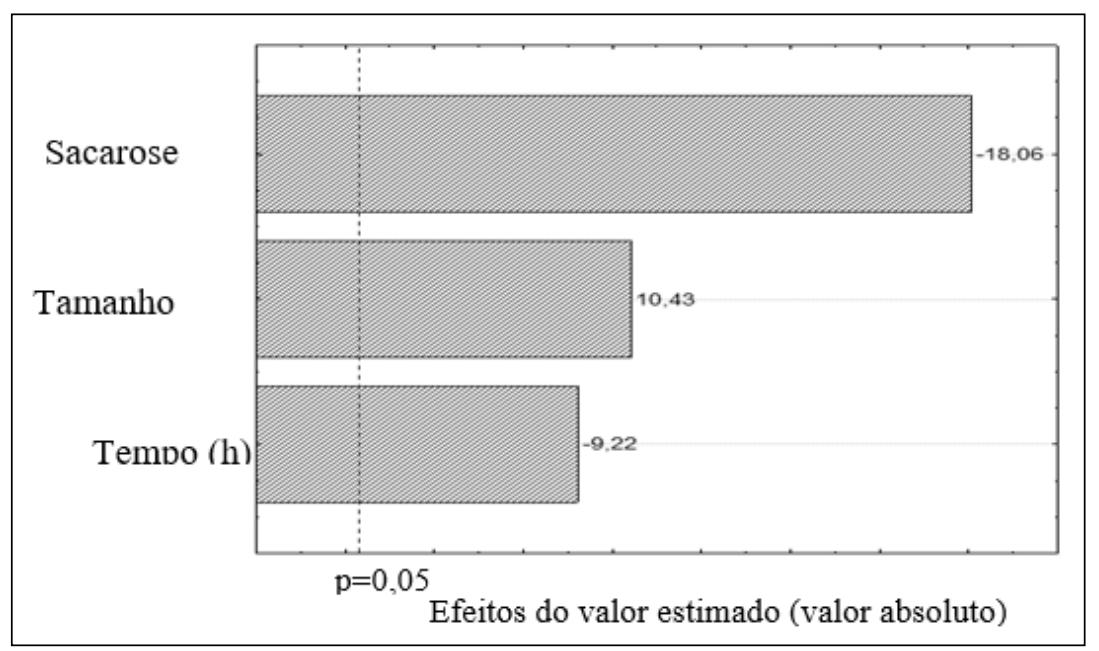

Fonte: Próprio autor, 2017.

Dessa forma, verificou-se que a menor umidade (Experimento 4) foi obtida nas condições de desidratação osmótica contendo concentração da solução de sacarose de $70 \%$, tempo de incubação de 14 horas e pedaços de manga de $0,5 \mathrm{~cm}$.

\subsection{Caracterização físico-química}

Para análise físico-química da manga in natura e desidratada osmoticamente, foram realizadas análises de cinzas, $\mathrm{pH}$ e acidez em porcentagem de ácido cítrico. Os dados analisados estão compilados na Tabela 5.

Tabela 5: Características físico-químicas da manga espada in natura e desidratada

\begin{tabular}{l|c|c}
\hline \multirow{2}{*}{ Parâmetros } & in natura & Desidratada osmoticamente \\
\cline { 2 - 3 } & Média \pm Desvios Padrão & Média \pm Desvios Padrão \\
\hline Acidez (\% ácido cítrico) & $0,54 \pm 0,02$ & $0,29 \pm 0,02$ \\
\hline $\mathrm{pH}$ & $3,67 \pm 0,01$ & $4,29 \pm 0,07$ \\
\hline Cinzas (\%) & $0,38 \pm 0,03$ & $0,48 \pm 0,03$ \\
\hline
\end{tabular}

Fonte: Próprio autor, 2017.

Como pode ser observado, o processo de desidratação osmótica reduziu a acidez em ácido cítrico em relação ao fruto in natura, sendo que este fato pode ter ocorrido devido à solubilidade dos ácidos orgânicos em água, em especial do ácido cítrico, permitindo a lixiviação deste da fruta para a solução 
de sacarose (QUEIROZ et al., 2007; MENDES et al., 2013). A redução da acidez também foi observada por Germer et al., (2011) ao desidratarem pêssego pelo processo de imersão-impregnação, onde ocorreu perda de ácidos orgânicos por parte da fruta no decorrer da desidratação osmótica.

Paglarini et al., (2015) e Mendes et al., (2013) também observaram uma redução na acidez em ácido cítrico ao avaliar a desidratação osmótica do araçá-pêra e laranja, respectivamente. Em contrapartida, houve um aumento do teor de cinzas devido a redução do teor de água no alimento desidratado, concentrando o conteúdo mineral ou as cinzas. Segundo Ramos et al., (2008), a secagem resulta na concentração de solutos, de modo que proteínas, carboidratos, vitaminas, minerais e outros componentes podem estar presentes em maiores quantidades, por unidade de massa, no alimento desidratado em relação ao alimento in natura. Além disso, os valores obtidos para cinzas, ou matéria estão de acordo com os resultados obtidos Elias et al., (2008) e por Caneppele et al., (2001) para caqui e bananas, submetidos a desidratação osmótica seguida de secagem convectiva.

$\mathrm{O}$ pH da manga desidratada também sofreu uma elevação, sendo que o mesmo comportamento foi observado por Santos et al., (2011) ao avaliarem o efeito da desidratação osmótica em chips de batata doce.

\subsection{Cinética de Secagem}

A secagem da manga espada foi realizada em estufa com circulação de ar na velocidade de $3,2 \mathrm{~m} / \mathrm{s}$, nas temperaturas de $60{ }^{\circ} \mathrm{C}$ e $40{ }^{\circ} \mathrm{C}$. O critério de parada de secagem foi estipulado pelo tempo necessário para o produto atingir sua estabilidade em relação à perda de água.

Na Figura 3, podem ser observadas as curvas de secagem a $60{ }^{\circ} \mathrm{C}$ e 40 ${ }^{\circ} \mathrm{C}$ da manga desidratada (70 \%, tempo de incubação de 14 horas e pedaços de manga de $0,5 \mathrm{~cm}$ ) e in natura. 
Figura 3: Curva de secagem (a) $60^{\circ} \mathrm{C} \mathrm{e} \mathrm{(b)} 40^{\circ} \mathrm{C}$ das amostras de manga in natura e desidratada osmoticamente

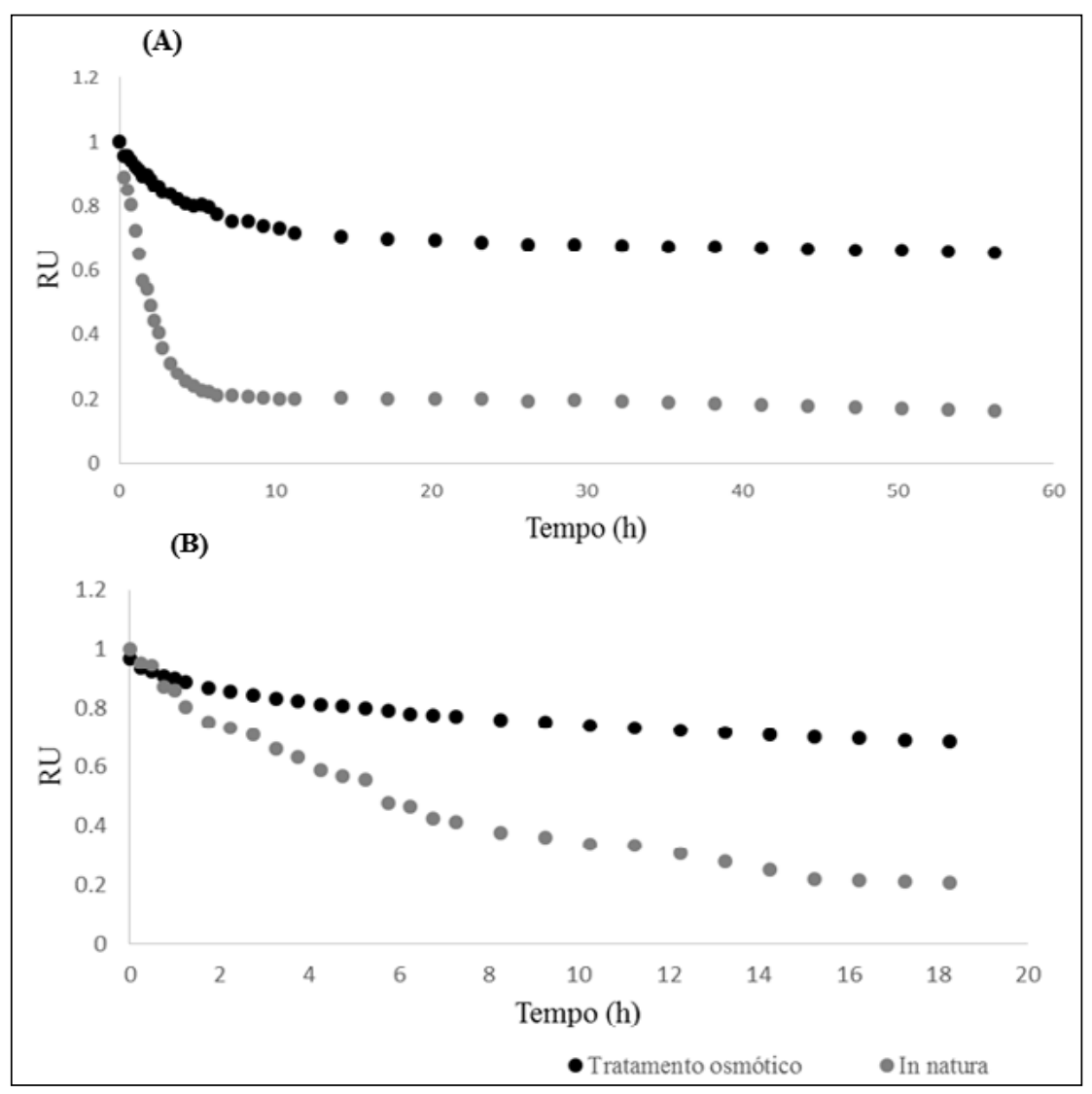

Fonte: Próprio autor, 2017.

Os resultados das amostras submetidas a secagem mostraram que a 40 ${ }^{\circ} \mathrm{C}$ houve uma perda de água mais rápida em comparação com a temperatura de $60{ }^{\circ} \mathrm{C}$. Além disso, em ambas as temperaturas, a manga submetida ao tratamento osmótico apresentou uma razão entre a quantidade de água final e inicial superior a manga in natura, efeito provavelmente associado ao teor de água superior da fruta in natura e assim consequentemente, apresentar maior teor de água livre, água de mais fácil eliminação no decorrer da secagem (FELLOWS, 2006).

A amostra desidratada osmoticamente perdera água livre durante o processo de osmose feito anteriormente a secagem. Além disso, no processo de desidratação osmótica os frutos podem ter desenvolvido uma camada superficial, dificultando a saída da água do interior do fruto, sendo que o mesmo foi observado no estudo realizado por El-Aquar e Murr (2003), que compararam a cinética de secagem de cubos de mamão in natura e pré-desidratados em 
solução de sacarose a 70 \%, observaram que a utilização de uma etapa prévia de desidratação osmótica influenciou negativamente a velocidade de secagem por convecção.

O processo de secagem aconteceu apenas no período decrescente, a mesma é controlada pelo líquido contido no interior do fruto até a superfície onde acontece a evaporação e sendo assim logo após algumas horas o período de secagem permanece constante. Estes resultados se assemelham com os trabalhos realizados sobre a secagem de diversos produtos como milho-pipoca (CORREA; MACHADO; ANDRADE, 2001) e trigo (MOHAPATRA; RAO, 2005).

\section{CONCLUSÃO}

Diante dos resultados obtidos conclui-se que a concentração da solução osmótica (sacarose), tempo de imersão e tamanho do fruto são as variáveis que mais influenciam no processo de desidratação osmótica, sendo observado a maior desidratação após imersão dos frutos por 14 horas, no tamanho de $0,5 \mathrm{~cm}$ e concentração de $70 \%$.

Pode-se observar uma ligeira alteração nas características físico-químicas da manga após o processo de desidratação, sendo observado um aumento do teor de cinzas e redução da acidez da fruta. Dessa forma, o processo de desidratação osmótica pode ser considerado como uma alternativa para a conservação da manga espada, uma vez que é simples e capaz de reduzir a umidade da manga.

\section{REFERÊNCIAS}

ARAÚJO, Paulyanna M. Estudo da desidratação osmótica da cenoura (Daucus carota) em fatias. 2010. 136 f. Dissertação (Mestrado em Pesquisa e Desenvolvimento de Tecnologias Regionais) - Universidade Federal do Rio Grande do Norte, Natal, 2010.

BEZERRA, Tânya S. Comportamento higroscópico de pós de diferentes variedades de manga (Magifera indica L.). Dissertação (Mestrado em Tecnologia de Alimentos)Universidade Federal do Ceara, UFCE. Fortaleza, 2009.

CANEPPELE, C. et al. Avaliação da eficiência de secagem em secadores de frutas por convecção natural. Revista Brasileira de Armazenamento, Viçosa, v. 26, n. 1, p. 46-52, 2001.

CORREIA, Paulo C.; MACHADO, Patrícia F.; ANDRADE, Ednilton T. Cinética de secagem e qualidade de grãos de milho-pipoca. Ciências Agrotécnica, Lavras, v. 25, n.1, p.134-142, 2001. 
DAMIANI, Clarissa et al. Análise física, sensorial e microbiológica de geléias de manga formuladas com diferentes níveis de cascas em substituição à polpa. Revista Ciência Rural, Santa Maria, v. 38, n.5, p.1418-1423, 2008.

EL-AQUAR, Ânoar A.; MURR, Fernanda E. X. Estudo e modelagem da cinética de desidratação osmótica do mamão formosa (Carica papaya L.). Ciência e Tecnologia de Alimentos, Campinas, v. 23, n. 1, p. 69-75, 2003.

ELIAS, Nathalia. F. et al. Avaliação nutricional e sensorial de caqui cv Fuyu submetido à desidratação osmótica e secagem por convecção. Ciência e Tecnologia de Alimentos, Campinas, v. 28, n. 2, p. 322-328, 2008.

FELLOWS, Peter J. Tecnologia do processamento de alimentos: princípios e prática. 2. ed. Porto Alegre: Artmed, 2006. 602 p.

GERMER, S. P. M. et al. Desidratação osmótica de pêssegos em função da temperatura e concentração do xarope de sacarose. Revista Brasileira de Engenharia Agrícola e Ambiental, v.15, n.2, p.161-169, 2011.

INSTITUTO BRASILEIRO DE GEOGRAFIA E ESTATÍSTICA (IBGE). Censo 2010. Disponível em: <http:/ / www.ibge.gov.br> Acesso em: 28 de nov. de 2017.

INSTITUTO ADOLFO LUTZ. Métodos físico-químicos para análise de alimentos. Edição IV, Brasília: Instituto Adolfo Lutz, 2008.

MENDES, Gabriela R. L. et al. Condições para desidratação osmótica de laranjas e as propriedades funcionais do produto. Revista Brasileira de Engenharia Agrícola e Ambiental, v.17, n.11, p.1210-1216, 2013.

MOHAPATRA, Debabandya.; RAO, Pavuluri S. A thin layer drying model of parboiled wheat. Journal of Food Engineering, v.66, p.513-518, 2005.

PAGLARINI, Camila S. et al. Efeito das condições de desidratação osmótica na qualidade de passas de araçá-pêra. Revista Brasileira de Tecnologia Agroindustrial, v.9, n. 2, p. 1945-1961, 2015.

QUEIROZ, Valéria A. V. et al. Desidratação por imersão-impregnação e secagem por convecção de goiaba. Pesquisa Agropecuária Brasileira, Brasília, v. 42, n.10, p.14791486, 2007.

RAMOS, Afonso M. et al. Efeito do tipo de embalagem e do tempo de armazenamento nas qualidades físico-química e microbiológica de abacaxi desidratado. Alimentos e Nutrição, Araraquara, v. 19, n. 3, p. 259- 269, 2008.

SANTOS, Cleydilaine C. et al. Composto voláteis de cultivares de manga (Mangifera indica L.) de Mato Grosso do Sul. Ciência Agrárias, Anais 9º ENIC, n. 3, Goiânia. 2011. 
SANTOS, Marília A. et al. Efeito da desidratação osmótica seguida de fritura nas características físico-químicas de chips de batata-doce bioforticada. Enciclopédia Biosfera, Goiânia, v.7, n. 13, p. 1434-1442, 2011.

SILVA, Natacia S. et al. Elaboração de Bebidas Alcoólicas Fermentada a Partir do Suco de Manga Rosa (Mangifera indica L). Revista Brasileira de Tecnologia Agroindustrial, v. 5, n.1, p. 367-378, 2011.

SOUSA NETO, Manoel A. et al. Desidratação osmótica de manga seguida de secagem convencional: Avaliação das variáveis de processo. Revista Ciência e Agrotecnologia, v. 29, n.5, p.1021-1028, 2005. 